\title{
Ciborinia camelliae (Sclerotiniaceae) Induces Variable Plant Resistance Responses in Selected Species of Camellia
}

\author{
Matthew Denton-Giles, Rosie E. Bradshaw, and Paul P. Dijkwel
}

Institute of Molecular Biosciences, Massey University, Palmerston North, Manawatu, 4442 New Zealand. Accepted for publication 6 February 2013.

\begin{abstract}
Denton-Giles, M., Bradshaw, R. E., and Dijkwel, P. P. 2013. Ciborinia camelliae (Sclerotiniaceae) induces variable plant resistance responses in selected species of Camellia. Phytopathology 103:725-732.

Ciborinia camelliae is the causal agent of Camellia flower blight. This fungal pathogen is a significant pest of the Camellia floriculture industry because it specifically infects the floral tissue of ornamental camellia cultivars leading to the rapid development of necrotic lesions and blight. This study aims to characterize natural resistance to Ciborinia camelliae within a selection of Camellia spp. Based on macroscopic lesion develop-

revealed several hallmarks of induced plant resistance, including papillae formation, $\mathrm{H}_{2} \mathrm{O}_{2}$ accumulation, and localized cell death. The compatible Camellia Nicky Crisp-Ciborinia camelliae interaction failed to trigger a similar resistance response. Ciborinia camelliae growth in compatible tissue demonstrated a switch from biotrophy to necrotrophy, evident from the simultaneous development of secondary hyphae and necrotic lesions. Extension of resistance analyses to 39 additional Camellia spp. identified variable levels of resistance within the Camellia genus. The evidence presented supports a resistance breeding strategy for controlling Ciborinia camelliae on ornamental Camellia hybrids.
\end{abstract} ment, Camellia 'Nicky Crisp' and Camellia lutchuensis were chosen as compatible and incompatible hosts, respectively. Microscopic analyses of the incompatible Camellia lutchuensis-Ciborinia camelliae interaction
Additional keywords: appressoria, hypersensitive response.
The genus Camellia is the largest and most economically important of the family Theaceae $(5,45)$. The two most economically important species are Camellia sinensis var. sinensis and Camellia sinensis var. assamica, which are cultivated for the production of tea (5). Camellia spp. are also valued as ornamental shrubs, being especially popular in temperate regions of the world, including North America, Europe, and Australasia $(1,37)$. Intraspecific and interspecific hybrids of Camellia japonica, Camellia sasanqua, and Camellia reticulata form the basis of more than 20,000 registered ornamental Camellia cultivars (33).

Many ornamental Camellia spp. and cultivars are susceptible to infection by the fungal phytopathogen Ciborinia camelliae L. M. Kohn (Sclerotiniaceae) (21). This pathogen specifically infects the floral tissue of Camellia spp. following the dissemination of ascospores from sclerotia-germinated apothecia. Commonly referred to as "Camellia flower blight," compatible interactions result in the development of brown petal lesions, blight, and premature flower fall (21). Prior to the 1990s, Ciborinia camelliae had been described only in Japan and North America $(11,13)$. However, recent introductions have been reported in New Zealand (1993) and Europe (1999) and the disease is now widespread in these regions (37).

A number of methods have been tried to control Ciborinia camelliae infection, including pest management approaches (42), fungicide applications (37), and the use of biological control agents $(43,44)$. Although several of these strategies have shown promise in reducing the infection rate of Ciborinia camelliae,

Corresponding author: P. P. Dijkwel; E-mail address: P.Dijkwel@massey.ac.nz

* The $\boldsymbol{e}$-Xtra logo stands for "electronic extra" and indicates that the online version contains three supplementary figures and two supplementary tables. Figures 1 and 3 appear in color online.

http://dx.doi.org/10.1094/PHYTO-11-12-0289-R

(C) 2013 The American Phytopathological Society none have been able to stop the annual reincursion of this pathogen into treated areas. The discovery of natural resistance to Ciborinia camelliae in several species of Camellia has revealed a new opportunity for controlling this pathogen on ornamental Camellia hybrids (36).

The identification of incompatibility in several Camellia spp.Ciborinia camelliae interactions suggests that the effector repertoire of Ciborinia camelliae is not adapted for all species of the genus Camellia. The attempted colonization of a plant by a nonadapted microbial pathogen can result in the induction of plant resistance $(14,39)$. Induced plant resistance responses are under complex genetic control and are mediated by the plant immune system $(16,28)$. The plant immune system consists of two branches that have separate molecular mechanisms for detecting pathogen infection (16). The first branch recognizes conserved microbial-associated molecular patterns (MAMPS) at the cell wall, through the action of pathogen recognition receptors (PRRs) (10). MAMP-triggered immunity (MTI) characteristically stimulates downstream defense responses that include cell wall modifications, papillae formation, phytoalexin biosynthesis, and reactive oxygen species (ROS) accumulation $(15,25,38)$. A hostadapted pathogen that successfully suppresses MTI through the action of its effectors is said to have established effector-triggered susceptibility (ETS) (16). The second branch of the plant immune system involves the detection of pathogen effector molecules by plant resistance (R) proteins. Effector-triggered immunity (ETI) characteristically culminates in a hypersensitive response (HR) and is a more rapid response than MTI (16). Many plant-pathogen interactions stimulate characteristics of both branches of the plant immune system $(15,31)$.

In the present work, we aimed to characterize the host responses associated with the compatible Camellia 'Nicky Crisp'Ciborinia camelliae and incompatible Camellia lutchuensisCiborinia camelliae interactions. In addition, we sought to identify further sources of resistance to Ciborinia camelliae within the genus Camellia. 


\section{MATERIALS AND METHODS}

Plant and pathogen material. Five-year-old shrubs of Camellia Nicky Crisp (Camellia japonica $\times$ Camellia pitardii var. pitardii) $(n=12)$ and Camellia lutchuensis $(n=12)$, used for flower petal production, were maintained in a sealed glasshouse at outside ambient temperature. All other Camellia petals were collected from species growing in the Auckland Botanic Gardens (ABG) (Supplementary Table 1). Flowers of similar developmental age were chosen for infection experiments, as determined by the presence of undehisced pollen. Isolates of Ciborinia camelliae were collected from wild populations located in the Massey University Arboretum (coordinates 40 38 $37^{\prime \prime} \mathrm{S}$ and $176^{\circ} 62^{\prime} 12^{\prime \prime}$ E) immediately prior to use. Freshly collected apothecia were inverted in 50-ml universal bottles and left at room temperature to release their ascospores over a period of 2 days. Ascospores were suspended in sterile MilliQ water and diluted to a concentration of $8 \times 10^{5}$ spores $/ \mathrm{ml}$ immediately prior to petal inoculation.

Ascospore infection of detached Camellia petals. Ascospores were sprayed onto detached Camellia petals using a $15 \mathrm{ml}$ atomizer with an estimated coverage of 500 to 1,000 ascospores $/ \mathrm{cm}^{2}$. Sterile MilliQ water was used for all mock inoculations. Trays of inoculated petals were placed into plastic bags and incubated in a growth cabinet at $21^{\circ} \mathrm{C}$ under a photoperiod of $12 \mathrm{~h}$ of light and $12 \mathrm{~h}$ of darkness at a light intensity of $60 \mu \mathrm{E}$. Petals that potentially developed infection from preinoculation contamination (based on observations of mock inoculated control petals) were
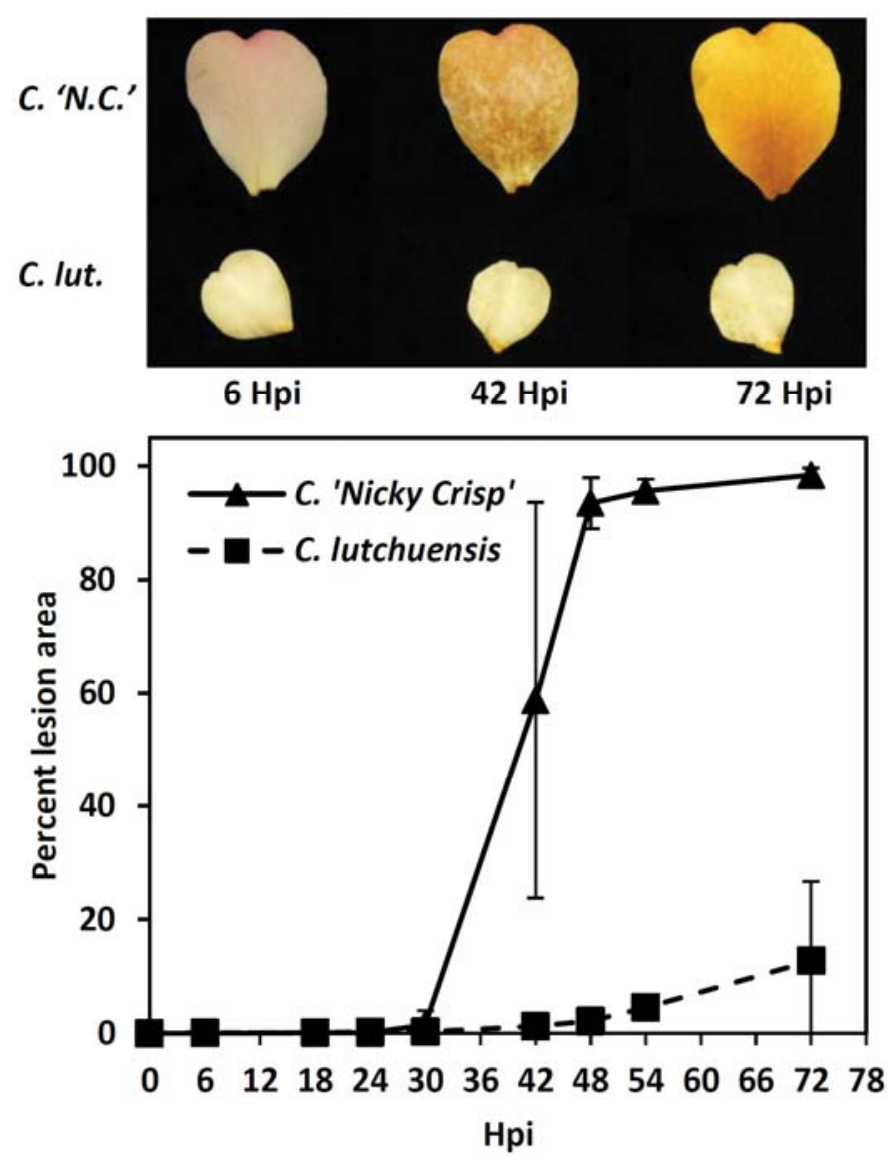

Fig. 1. Macroscopic assessment of Ciborinia camelliae infection on petals of Camellia 'Nicky Crisp' and Camellia lutchuensis. Images show disease progression in infected petals of Camellia 'Nicky Crisp' (C. 'N.C.') and C. lutchuensis $(C$. lut.) at 6,42 , and $72 \mathrm{~h}$ postinoculation (hpi). The graph shows percent petal lesion area at 6, 18, 24, 30, 42, 48, 54, and $72 \mathrm{hpi}$. Each data point corresponds to the mean percentage lesion area of six single-petal replicates \pm one standard deviation. omitted from all subsequent analyses. Petals were removed for macroscopic and microscopic analysis at predetermined time intervals.

Image analysis. Images used for macroscopic lesion analysis were taken using a Fujifilm FinePix Z digital camera. In total, six single-petal replicates from two separate experiments were used to profile lesion development in Camellia Nicky Crisp and Camellia lutchuensis (Fig. 1). Three single-petal replicates were used for ABG species lesion analysis unless otherwise stated. ImageJ software (NIH; http://rsb.info.nih.gov/ij/) was used to quantify lesion area at $6,18,24,30,42,48$, and 72 h postinoculation (hpi) using the "Color Threshold" tool. Lesion pixel color was calibrated by measuring the pixel color range within fully established petal lesions.

Histology and microscopy. Light microscopy (LM). Petal tissue discs (10 $\mathrm{mm}$ in diameter) were excised, fixed, and cleared in 3:1 ethanol/acetic acid overnight. Discs were then stained in a solution of $0.01 \%$ (wt/vol) Trypan blue (Sigma-Aldrich, St. Louis) in lactophenol for 2 to $3 \mathrm{~h}$, washed twice in MilliQ water, and stored in $30 \%$ (wt/vol) glycerol until examined. For dual 3,3'diaminobenzidine (DAB) (Sigma-Aldrich) and Trypan blue staining, 10-mm-diameter discs were excised from live tissue $2 \mathrm{~h}$ before their predetermined assessment time, vacuum infiltrated with a solution of DAB at $1 \mathrm{mg} / \mathrm{ml}$ and $\mathrm{pH} \mathrm{5.0,} \mathrm{and} \mathrm{dark} \mathrm{incu-}$ bated. At the time of assessment, discs were fixed and cleared in 3:1 ethanol: acetic acid and stained with Trypan blue. A Leica DM500 light microscope equipped with a Leica D5C295 digital camera (Leica, Germany) was used for microscopic analysis and image capture. Quantification of microscopic parameters for Camellia Nicky Crisp $(n=5)$ and Camellia lutchuensis $(n=5)$ was performed by assessing 50 germinated ascospores at 12, 24, 36, and 48 hpi (Table 1). Ascospores were considered to have germinated if their oval shape had become polarized or if primary hyphae were visible. Papilla formation was quantified by counting the number of interactions that produced a DAB-stained halo at the point of penetration. Intercellular $\mathrm{H}_{2} \mathrm{O}_{2}$ was quantified by counting the number of interactions with DAB staining at the cellular periphery of afflicted epidermal cells. Collapsed or DABstained cells were quantified by counting the number of interactions that exhibited a depressed cuticle and simultaneously exhibited DAB staining. Lengthened primary hyphae were quantified by counting the number of interactions that produced a primary hypha with a length greater than its associated ascospore. Subcuticular hyphae were quantified by counting the number of interactions that gave rise to hyphae below the petal cuticle and, in turn, grew as far as the epidermal intercellular space. Subepidermal hyphae were quantified by counting the number of interactions that successfully gave rise to hyphae that were visible at a subepidermal focal plane. ABG petal samples ( $n=3$ unless stated) were analyzed similarly at $24 \mathrm{hpi}$, with the exception that all analyses were performed blind.

Confocal laser scanning microscopy (CLSM). Plant cell autofluorescence associated with Ciborinia camelliae infection was captured using a Leica SP5 DM6000B confocal microscope (Leica). An argon laser was used for excitation at $488 \mathrm{~nm}$ and epidermal cell autofluorescence was collected using photomultiplier tube detectors set for detection between 499 and $676 \mathrm{~nm}$. A Z-stack of 41 sequential scans through the infected epidermal cell at intervals of $0.46 \mu \mathrm{m}$ was performed in order to determine the localization of epidermal cell autofluorescence and to visualize papilla in the cell wall.

Scanning electron microscopy (SEM). SEM was performed as described by Eaton et al. (7). Petal tissue was fixed in $0.1 \mathrm{M}$ phosphate buffer ( $\mathrm{pH} 7.2$ ) containing $3 \%$ glutaraldehyde and $2 \%$ formaldehyde for $24 \mathrm{~h}$. Following fixation, tissue was washed with $0.1 \mathrm{M}$ phosphate buffer ( $\mathrm{pH}$ 7.2), passed through an ethanol series, critical point dried using liquid $\mathrm{CO}_{2}$, mounted on stubs, and sputter coated with gold particles. An FEI Quanta 200 envi- 
ronmental scanning electron microscope with digital image capture (FEI, Eindhoven, The Netherlands) was used to visualize Camellia Nicky Crisp-Ciborinia camelliae and Camellia lutchuensis-Ciborinia camelliae interactions at $24 \mathrm{hpi}$.

Statistical analysis. Percentage data for macroscopic and microscopic analyses were calculated from biological replicates and presented as mean percentage \pm one standard deviation. The heat-map was generated from mean percentage values for each microscopic parameter using $\mathrm{MeV}$ software (Institute for $\mathrm{Ge}$ nomic Research, Rockville, MD; http://www.tm4.org/mev/). Data associated with intercellular $\mathrm{H}_{2} \mathrm{O}_{2}$ and collapsed or DAB-stained cells were not included in the heat-map because they were not significantly different from the compatible control. Papilla formation data were converted to papilla absence (inverse measurement of papilla formation) in order to conform with the high-to-low trend of the other heat-map data. The software package $R(\mathrm{R}$ Foundation for Statistical Computing, Vienna, Austria; http:// www.r-project.org/) was used for statistical analyses of the data. To compare significance between quantified microscopic resistance parameters, raw data from the Camellia Nicky Crisp ABG control was compared with other Camellia spp. using multiple two-tailed Student's $t$ tests. $P$ values were adjusted for multiple testing using a false discovery rate correction (4). One-way analysis of variance (ANOVA) and Tukey's range test were used to determine whether Camellia sections were significantly different from each other for each microscopic resistance parameter.

\section{RESULTS}

Camellia genotype influences macroscopic disease development. Ciborinia camelliae infection was quantified macroscopically by spray inoculating detached petals of Camellia Nicky Crisp and Camellia lutchuensis with inoculum solution at $8 \times 10^{5}$ ascospores/ml. Camellia Nicky Crisp petals formed lesions 24 hpi (Fig. 1). By 72 hpi, these lesions had coalesced to cover $>95 \%$ of the petal area. In contrast, Camellia lutchuensis petals failed to develop any detectable lesions before $42 \mathrm{hpi}$ and reached a maximum lesion area of $13 \%$ by 72 hpi. Mock-infected petals failed to produce any lesions in both genotypes, indicating that foreign ascospore levels were low (data not shown). Based on this bioassay, Ciborinia camelliae was deemed to be compatible with Camellia Nicky Crisp and incompatible with Camellia lutchuensis.

Compatible Camellia Nicky Crisp-Ciborinia camelliae interactions involve cuticle penetration, intercellular growth, and secondary hypha development. Microscopic characterization of compatible Camellia Nicky Crisp-Ciborinia camelliae interactions involved a combination of SEM and LM. Direct penetration of the petal cuticle by Ciborinia camelliae was observed at 24 hpi using SEM (Fig. 2A). Penetration was achieved by the action of an appressorium-like structure at one end of the germinated ascospore. Instances where penetration occurred after a period of surface hyphal growth were also observed (Fig. 2B).
Histological analysis indicated that cuticle penetration was followed by subcuticular growth of the primary hypha (Fig. 3A). Upon reaching the epidermal intercellular space, subcuticular hyphae commenced an apoplastic growth phenotype. Apoplastic growth was maintained in the mesophyll and lower epidermal tissue prior to 24 hpi (Fig. 3B; Supplementary Figure 1). The majority of in planta fungal hyphae were localized to the petal mesophyll tissue at $24 \mathrm{hpi}$ (Fig. 3C). From $36 \mathrm{hpi}$, a change in fungal development in the epidermal tissue was observed, underlined by broadening of subcuticular primary hyphae and initiation of secondary hyphal development (Fig. 3D). As secondary hyphal growth radiated, some of the hyphae became aerial (Supplementary Figure 2). This change in hyphal growth correlated with the proliferation of lesions observed in the compatible Camellia Nicky Crisp detached petal bioassay (Fig. 1).

The incompatible Camellia lutchuensis-Ciborinia camelliae interaction induces characteristic plant defense responses. A series of temporal microscopic analyses were carried out to investigate the mechanism of defense in petal tissue of Camellia lutchuensis. SEM analysis revealed that the petal cuticle of the incompatible tissue was also penetrated directly by Ciborinia camelliae (Fig. 2D). However, unlike the compatible interaction, penetration was frequently accompanied by the formation of plant papillae in epidermal cell walls (Fig. $3 \mathrm{E}$ and Table 1). DAB staining revealed an accumulation of $\mathrm{H}_{2} \mathrm{O}_{2}$ at the site of papilla formation as well as at the periphery of the epidermal cell. This is consistent with reports that describe papilla formation and $\mathrm{H}_{2} \mathrm{O}_{2}$ accumulation in response to attempted pathogen penetration (15, 38). An orthogonal cross-section through a single papilla showed thickening of the cell wall, further confirming this structure as a papilla (Fig. 2E and $E^{\prime}$ ). Quantification of the number of papillae showed that they increased significantly $(P<0.01)$ during the incompatible interaction at 12 to 48 hpi (Table 1). $\mathrm{H}_{2} \mathrm{O}_{2}$ appeared to diffuse from the afflicted cell to the walls of neighboring epidermal cells (Fig. 3F). Intercellular $\mathrm{H}_{2} \mathrm{O}_{2}$ was occasionally observed during the Camellia Nicky Crisp-Ciborinia camelliae compatible interaction, suggesting that this phenotype is not exclusive to the Camellia lutchuensis-Ciborinia camelliae incompatible interaction (Table 1).

A small percentage of Camellia lutchuensis epidermal cells showed a collapsed phenotype in response to infection by Ciborinia camelliae from 24 hpi (Fig. 2C; Table 1). Collapsed cells stained intensely with $\mathrm{DAB}$, indicating that $\mathrm{H}_{2} \mathrm{O}_{2}$ levels were elevated (Fig. 3). In contrast, collapsed cells were not observed during the compatible Camellia Nicky Crisp-Ciborinia camelliae interaction (Table 1).

Hyphal development was used as a second, DAB-independent strategy for quantifying resistance to Ciborinia camelliae in planta. The number of germinated ascospores that produced hyphae that were greater than their ascospore length increased over time for both compatible and incompatible interactions. By 36 hpi, $99 \%$ of primary hyphae were longer than their associated ascospores in susceptible tissue, whereas only $46 \%$ reached this

TABLE 1. Quantification of microscopic parameters associated with Ciborinia camelliae development in compatible Camellia 'Nicky Crisp' and incompatible Camellia lutchuensis petal tissue ${ }^{\mathrm{a}}$

\begin{tabular}{|c|c|c|c|c|c|c|c|}
\hline \multirow[b]{2}{*}{ Microscopic parameters } & \multicolumn{3}{|c|}{ Camellia Nicky Crisp } & \multicolumn{4}{|c|}{ C. lutchuensis } \\
\hline & 12 hpi & 24 hpi & 36 hpi & $12 \mathrm{hpi}$ & 24 hpi & 36 hpi & 48 hpi \\
\hline Papilla formation (\%) & $0 \pm 0$ & $0 \pm 0$ & $0 \pm 0$ & $50 \pm 12$ & $61 \pm 15$ & $76 \pm 7$ & $81 \pm 10$ \\
\hline Intercellular $\mathrm{H}_{2} \mathrm{O}_{2}(\%)$ & $0 \pm 0$ & $2 \pm 1$ & $6 \pm 7$ & $76 \pm 15$ & $90 \pm 6$ & $84 \pm 10$ & $88 \pm 10$ \\
\hline Lengthened primary hyphae (\%) & $87 \pm 7$ & $96 \pm 3$ & $99 \pm 1$ & $19 \pm 10$ & $52 \pm 20$ & $46 \pm 12$ & $31 \pm 18$ \\
\hline Subcuticular hyphal growth (\%) & $39 \pm 7$ & $91 \pm 4$ & $95 \pm 3$ & $1 \pm 1$ & $32 \pm 14$ & $33 \pm 14$ & $24 \pm 20$ \\
\hline Subepidermal hyphae (\%) & $0 \pm 0$ & $90 \pm 5$ & $86 \pm 22$ & $0 \pm 0$ & $1 \pm 1$ & $0 \pm 0$ & $2 \pm 2$ \\
\hline
\end{tabular}

${ }^{a}$ Data were collected at $12,24,36$, and $48 \mathrm{~h}$ postinoculation (hpi) for each microscopic parameter by assessing 50 germinated ascospores per biological replicate $(n=5)$. Data were not recorded for Camellia Nicky Crisp at 48 hpi due to disease-associated deterioration of the petal tissue. Mean percentage values are shown for each analysis \pm one standard deviation. 
threshold length in incompatible tissue (Table 1). We hypothesize that the formation of papillae contributed to the reduced hyphal length in incompatible tissue.

In support of this hypothesis, papilla formation inversely correlated with the number of subcuticular hyphae observed from 24 hpi (Table 1). Primary hyphae that managed to successfully penetrate the cuticle of Camellia lutchuensis epidermal cells established subcuticular growth. However, only $8 \%$ of these subcuticular hyphae developed into subepidermal hyphae by 48 hpi, suggesting that further defense mechanisms contribute to the restriction of fungal development in planta (Table 1).

Levels of incompatibility to Ciborinia camelliae vary within the genus Camellia. The frequency and intensity of Ciborinia camelliae incompatibility within the genus Camellia was assessed by extending the described analyses to 39 additional Camellia spp. collected from the ABG (Fig. 4). Color-converted mean percentage data depicted a gradient of resistance across the Camellia genus, from highly compatible phenotypes (light gray) to comparatively incompatible phenotypes (black). Statistical comparisons (Student's $t$ test) of the susceptible Camellia Nicky Crisp ABG genotype with each Camellia sp. further defined the levels of resistance within the Camellia genus (Fig. 4). Camellia lutchuensis, Camellia yuhsienensis, and Camellia transnokoensis were the most dissimilar to the Camellia Nicky Crisp ABG genotype, with significantly lower values for at least four of the five assessed parameters. Camellia xichengensis, Camellia mairei var. mairei, Camellia granthamiana, Camellia japonica subsp. japonica, Camellia sinensis var. sinensis, Camellia saluenensis, Camellia jinshajiangica, Camellia pitardii var. yunnanica, and Camellia puniceiflora were not significantly different from the Camellia Nicky Crisp ABG phenotype for all assessed parameters, indicating that these genotypes were compatible with Ciborinia camelliae. All other species exhibited a range of intermediate phenotypes with significance in one, two, or three of the five analyses. Statistical comparisons made between the data for the Camellia Nicky Crisp ABG genotype and the previously examined Camellia Nicky Crisp genotype showed no significant difference for the parameters presented (Fig. 4), suggesting that comparable analyses were reproducible. In addition to lesion analysis at $72 \mathrm{hpi}$, further observations of lesion development were made at $113 \mathrm{hpi}$. Camellia lutchuensis, Camellia yuhsienensis, Camellia transnokoensis, Camellia fraterna, Camellia transarianensis, Camellia longicarpa, and Camellia caudata were the only assessed species that failed to fully develop visible petal lesions by this time.

To determine whether the selected Camellia taxonomical sections were significantly different from each other, ANOVA was performed independently for each assessed parameter. Camellia sections appeared to be significantly different from one another for each of the assessed infection parameters, including lesion area at 72 hpi $(P<0.001)$, papillae absence $(P<0.001)$, lengthened primary hyphae $(P<0.001)$, subcuticular hyphae $(P<0.001)$, and subepidermal hyphae $(P<0.001)$. Further statistical analysis (Tukey's range test) highlighted specific differences between sections. Section Camellia was significantly different from section Paracamellia and section Theopsis for all of the quantified parameters (Supplementary Figure 3). Furthermore, sections Thea and Archecamellia were found to be not significantly different from section Camellia for all of the quantified parameters, although the number of replicate species within these two sections was low. This result suggests that resistance to Ciborinia camelliae is concentrated in certain sections of the genus Camellia.

\section{DISCUSSION}

Breeding pathogen-resistant crops has been a common goal of plant breeders for many years and still remains a preferred option
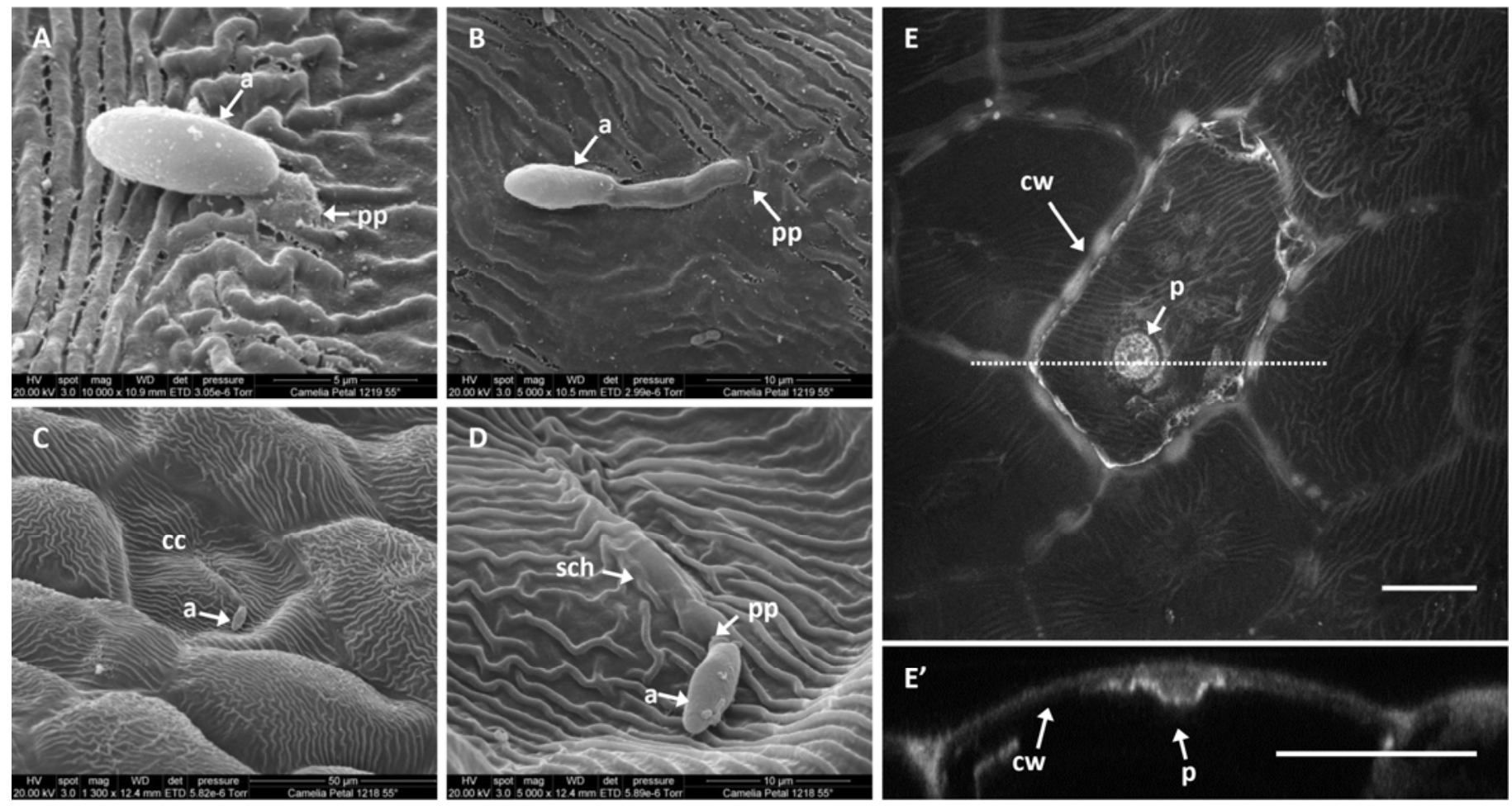

Fig. 2. Scanning electron and confocal micrographs show the development and interaction of Ciborinia camelliae with epidermal cells of A and B, Camellia 'Nicky Crisp' and C, D, E, and E', Camellia lutchuensis. Penetration of the petal cuticle by appressoria-like structures occurred directly from the ascospore (A) or following a period of hyphal growth (B). Incompatible interactions occasionally triggered epidermal cell collapse (C). A collapsed cell reveals the subcuticular growth habit of Ciborinia camelliae (D). A merged Z-stack of 41 images reveals localized autofluorescence associated with the cell wall and papilla of an afflicted epidermal cell (E). An orthogonal view of the same Z-stack through the site of papilla formation (indicated by the dotted line) reveals thickening of the cell wall at the position of papilla formation $\left(\mathrm{E}^{\prime}\right)$. Symbols: $\mathrm{a}=$ ascospore; $\mathrm{pp}=$ penetration point; $\mathrm{cc}=$ collapsed cell; $\mathrm{sch}=$ subcuticular hyphae; $\mathrm{cw}=\mathrm{cell}$ wall; $\mathrm{p}=$ papilla . All images were taken at $24 \mathrm{~h}$ postinoculation. Scale bar $=25 \mu \mathrm{m}$. 

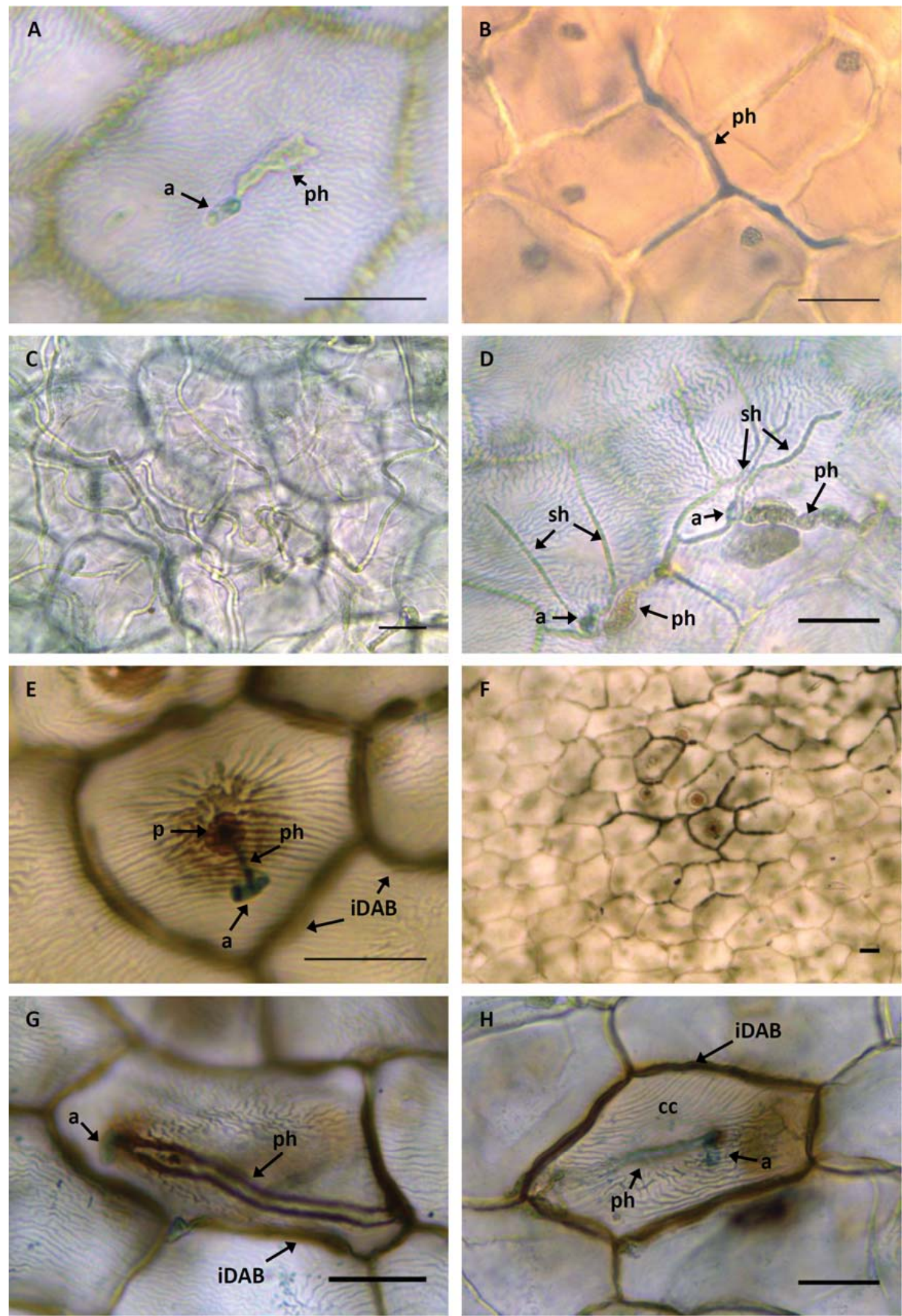

Fig. 3. Light micrographs showing the development and interaction of Ciborinia camelliae with A to D, compatible Camellia 'Nicky Crisp' and E to H, incompatible Camellia lutchuensis petal tissue. All samples were stained with Trypan Blue. Samples A and C to H were co-stained with 3,3'-diaminobenzidine (DAB). A, Penetration and subcuticular growth occurred prior to $12 \mathrm{~h}$ postinoculation (hpi) and failed to induce localized DAB staining in compatible Camellia Nicky Crisp petal tissue. B, A primary hypha exhibited apoplastic growth in the lower epidermis at $24 \mathrm{hpi}$. C, Translucent primary hyphae concentrated within the mesophyll tissue at 24 hpi. D, From 36 hpi, primary hyphae broadened and secondary hyphae developed. E, Papilla formation and intercellular DAB staining occurred in response to attempted cuticle penetration of $C$. lutchuensis petal tissue by Ciborinia camelliae, prior to 12 hpi. F, Intercellular DAB staining diffused outward from the afflicted epidermal cells. G, DAB staining localized to the cell wall of a subcuticular primary hypha at 24 hpi. H, Collapse of a DAB-stained epidermal cell was denoted by the lower focal plane of the cell's cuticle compared with surrounding cells at 36 hpi. Symbols: a = ascospore; ph = primary hypha; $\mathrm{sh}=$ secondary hypha; $\mathrm{p}=$ papilla; $\mathrm{iDAB}=$ intercellular $\mathrm{DAB} ; \mathrm{cc}=$ collapsed cell. Scale bar $=25 \mu \mathrm{m}$ 


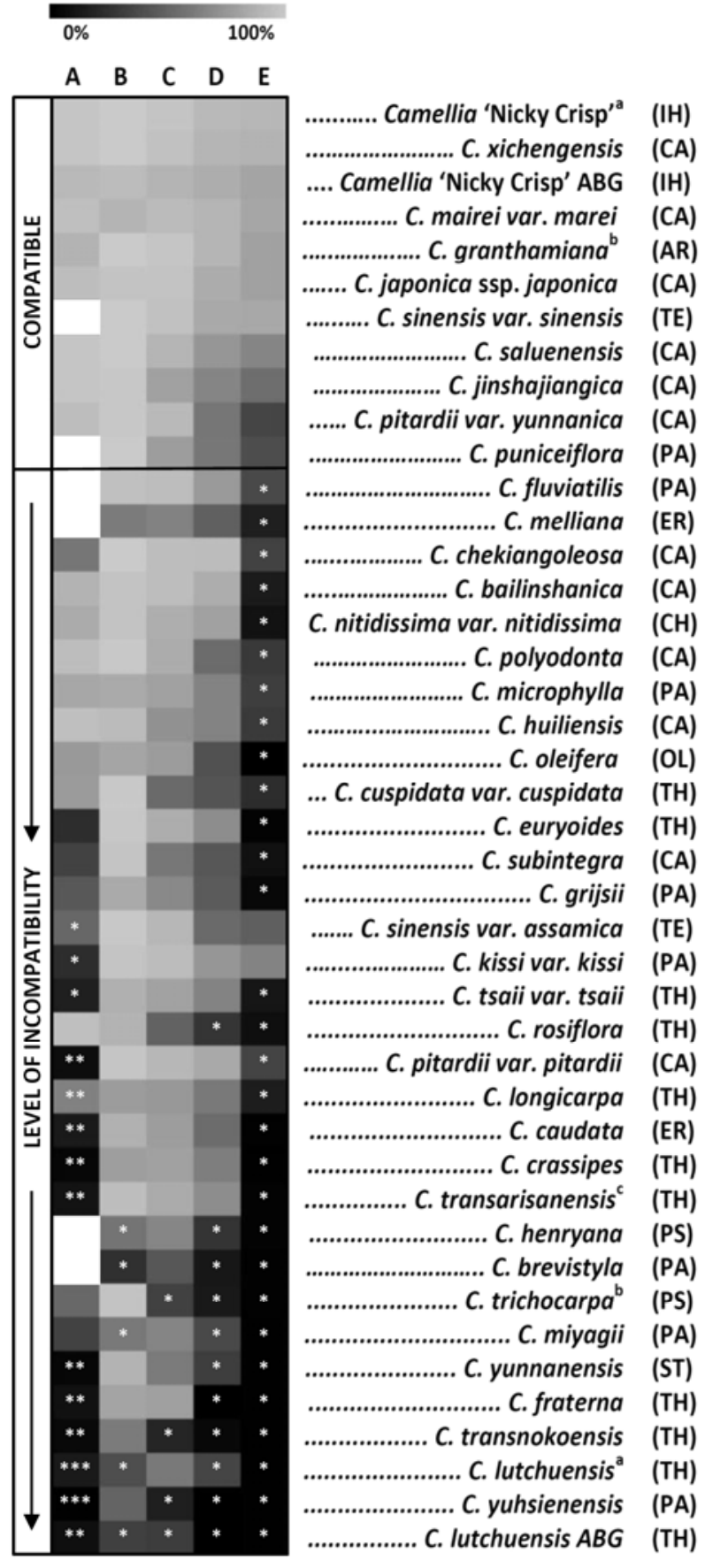

Fig. 4. Analysis of macroscopic and microscopic parameters in 40 species and one interspecific hybrid of Camellia. Column A = percent lesion area at $72 \mathrm{~h}$ postinoculation (hpi); $\mathrm{B}=$ papillae absence, $\mathrm{C}=$ lengthened primary hyphae, $\mathrm{D}=$ subcuticular hyphal growth, and $\mathrm{E}=$ subepidermal hyphae at $24 \mathrm{hpi}$. Tile color coding represents mean percentage data of three biological replicates (unless specified), ranging from highly compatible phenotypes (light gray) to comparatively incompatible phenotypes (black). White tiles represent "no data". Multiple two-tailed Student's $t$ tests were applied to raw data for each independent column, comparing each species with the susceptible Camellia 'Nicky Crisp' Auckland Botanic Gardens (ABG) genotype; *, **, and *** indicate values significantly less than Camellia Nicky Crisp ABG values at $P \leq 0.05,0.01$, and 0.001 respectively. The absence of asterisks represents no significant difference. Incompatible species were manually sorted and ranked based on the number of parameters that showed significant difference to the compatible control, Camellia Nicky Crisp ABG. Camellia sections are abbreviated as CA (Camellia), AR (Archecamellia), TE (Thea), CH (Chrysantha), PA (Paracamellia), OL (Oleifera), TH (Theopsis), ER (Eriandria), PS (Pseudocamellia), and ST (Stereocarpus). IH = interspecific hybrid. Superscript a: Data from original Camellia Nicky Crisp and Camellia lutchuensis samples were included for comparison. Superscript b: Column A data based on two biological replicates. Superscript c: Column B, C, D, and E data based on two biological replicates. for controlling plant disease (27). The discovery of natural resistance to Ciborinia camelliae in several species of the Camellia genus has revealed a new opportunity that has potential to control this pathogen using a traditional plant breeding strategy (36). In this study, we characterized the response of different Camellia genotypes to Ciborinia camelliae ascospore infection using both macroscopic and microscopic analyses. Compatible Camellia Nicky Crisp-Ciborinia camelliae interactions failed to display visible signs of resistance, which is consistent with the ETS hypothesis (16). In comparison, the incompatible Camellia lutchuensis-Ciborinia camelliae interaction showed strong signs of an induced resistance response. Assessment of a further 39 species of Camellia indicated that incompatibility is variable across the Camellia genus, with prevalence being higher in sections Theopsis and Paracamellia.

Penetration of the compatible Camellia Nicky Crisp petal cuticle by Ciborinia camelliae was achieved by appressoria-like structures that differ from the classic polarized appressoria produced by Colletotrichum and Magnaporthe spp. (20,47). However, Ciborinia camelliae appressoria-like structures were morphologically similar to those of other members of the Sclerotiniaceae family such as Botrytis cinerea, Sclerotinia sclerotiorum, and Monilinia fructicola $(9,17,23)$.

Following cuticle penetration of the susceptible tissue, initial asymptomatic growth of Ciborinia camelliae was confined to the apoplast. The well-characterized biotrophic fungus Cladosporium fulvum also confines its growth to the apoplast (6) and is thought to modulate the supply of host-derived nutrients as it grows $(34,35)$. The Avr2 and Avr4 effectors of Cladosporium fulvum have been shown to localize specifically in the apoplast of tomato leaves, where they act to indirectly inhibit plant protease activity (41) as well as recognition by PRRs (40). We hypothesize that Ciborinia camelliae may also produce apoplastic effectors that act to suppress MTI.

Following radiation of fungal hyphae in the apoplast, there is a switch in the growth habit of Ciborinia camelliae. Broadening of the subcuticular primary hyphae was observed at 36 hpi, together with the development of secondary hyphae in the vicinity of the cuticle penetration site (Fig. 3D). It is unclear whether the secondary hyphae of Ciborinia camelliae directly penetrate host petal cells. However, secondary hyphal growth appears to coincide with the first signs of macroscopic lesion development and necrosis. These observations are very similar to the growth habit of the hemibiotroph Colletotrichum acutatum (2). Initial biotrophic growth of Colletotrichum acutatum on almond petal tissue is confined to the apoplast, with broad intercellular subcuticular hyphae observed at 24 to $48 \mathrm{hpi}$. Similarly, the switch to necrotrophy is hallmarked by the initiation of secondary hyphae that directly penetrate host cells.

The Sclerotiniaceae family is well known as a necrotrophic-rich family of fungi, where necrotrophy is thought to be the ancestral state (3). It has recently been suggested that the well-established necrotroph $S$. sclerotiorum exhibits characteristics of biotrophy during its early pathogenic phase (46). Similarly, Ciborinia camelliae exhibits an asymptomatic biotrophic-like phase during establishment in planta that later transitions to necrotrophy. However, it is difficult to deduce whether this is a true hemibiotrophic lifestyle, based on observational data alone. Transcriptomic and genomic studies, such as those used to characterize and confirm the switch from biotrophy to necrotrophy in Colletotrichum higginsianum (30), would help to determine whether a similar switch occurs in Ciborinia camelliae.

Incompatibility observed during the Camellia lutchuensisCiborinia camelliae interactions resembled previous descriptions of induced plant resistance $(8,15,38)$. We observed the formation of preinvasive papillae in Camellia lutchuensis epidermal cells together with localized $\mathrm{H}_{2} \mathrm{O}_{2}$ at infection sites. Temporal quantification of papilla induction showed that the induced response to 
Ciborinia camelliae in plant epidermal cells was gradual over time (Table 1). This slow, steady increase in the intensity of the defense response is consistent with the gradual induction of MTIassociated responses (16).

The accumulation of $\mathrm{H}_{2} \mathrm{O}_{2}$ is thought to be involved in several processes during induced plant resistance, including cross-linking of the cell wall at the site of papilla formation (24); creation of a toxic, antimicrobial, high-ROS environment (26); and as part of the oxidative burst or HR mechanism (22). During the Camellia lutchuensis-Ciborinia camelliae interaction, we observed $\mathrm{H}_{2} \mathrm{O}_{2}$ localization at papillae formation sites, suggesting that crosslinking of the cell wall may occur during this interaction. However, it is unclear whether mechanical resistance is important for impeding the development of Ciborinia camelliae, because the initial subcuticular and apoplastic growth habit does not require penetration of the plant cell wall (Fig. 3A).

$\mathrm{H}_{2} \mathrm{O}_{2}$ is localized to the intercellular spaces of petal epidermal cells in proximity to cuticle penetration sites. Intercellular $\mathrm{H}_{2} \mathrm{O}_{2}$ appeared to diffuse outward from the penetration site, suggesting that its accumulation and localization is in response to cuticle penetration. Intercellular $\mathrm{H}_{2} \mathrm{O}_{2}$ was occasionally observed during penetration of some of the susceptible species, including the Camellia Nicky Crisp ABG control (Supplementary Table 2). It is plausible that some of the $\mathrm{H}_{2} \mathrm{O}_{2}$ observed during the plantpathogen interactions is derived from Ciborinia camelliae, because several members of the Sclerotiniaceae family are believed to produce $\mathrm{H}_{2} \mathrm{O}_{2}$ through the action of their own NADPH oxidase enzymes $(18,32)$ and via secreted oxalic-acid-mediated plant programmed cell death (19). Therefore, it is unclear whether intercellular $\mathrm{H}_{2} \mathrm{O}_{2}$ acts to suppress or promote the growth of Ciborinia camelliae in Camellia petal tissue.

A small percentage of epidermal cells exhibited DAB staining and a depressed cuticle during the Camellia lutchuensisCiborinia camelliae interaction. Previous reports have attributed observations of this kind to an ETI-mediated HR, which leads to localized cell death (38). This phenotype is consistent with the weak ETI previously observed in other induced plant-pathogen interactions, including the barley-powdery mildew interaction $(15,38)$ and the pepper-powdery mildew interaction $(12)$. The low frequency of the ETI response is thought to be due to weak recognition of effectors by plant $\mathrm{R}$ proteins (16). It is possible that ETI-associated necrosis contributed significantly to lesion area measurements shown in Figures 1 and 4, particularly during incompatible interactions.

In summary, these results suggest that Camellia lutchuensis defense responses to Ciborinia camelliae are initially induced at the point of attempted cuticle penetration. Furthermore, the impaired development of subcuticular and subepidermal fungal hyphae, together with localized cell death, indicates that Camellia lutchuensis-Ciborinia camelliae incompatibility involves multiple mechanisms of defense.

The extension of macroscopic and microscopic analyses to a further 39 species of Camellia revealed significant phenotypic variation in resistance to Ciborinia camelliae (Fig. 4). Camellia lutchuensis, Camellia yuhsienensis, and Camellia transnokoensis showed the strongest resistance phenotypes to Ciborinia camelliae and also failed to fully develop petal lesions by 113 hpi. The species Camellia fraterna, Camellia transarianensis, Camellia longicarpa, and Camellia caudata also failed to fully develop petal lesions by $113 \mathrm{hpi}$ but exhibited comparatively weaker resistance phenotypes than Camellia lutchuensis, Camellia yuhsienensis, and Camellia transnokoensis (Fig. 4). These results suggest that variable strengths of resistance to Ciborinia camelliae exist within the genus Camellia.

A large proportion of analyzed species showed defense responses but ultimately failed to resist the establishment of Ciborinia camelliae. This phenotype is consistent with the definition of basal resistance, which is described as resistance that reduces pathogen spread during compatible plant-pathogen interactions (29). Many Camellia spp. were able to delay the onset of necrotic lesion formation and the establishment of subepidermal hyphae compared with the compatible Camellia Nicky Crisp ABG genotype (Fig. 4). Consistent with Jones and Dangl's description of basal resistance (16), both MTI- and ETI-specific responses (papilla formation and HR) were observed in epidermal cells of these species (Fig. 4). Schulze-Lefert and Panstruga suggest a model whereby the contribution of the two branches of plant immunity to resistance varies depending on how well adapted a pathogen is to a potential host (31). In their model, high incompatibility between host and pathogen is due to a strong MTI response which, in turn, is a result of an ineffective pathogen-effector repertoire. Weaker incompatibility to a different host is the result of a weaker MTI response and a more effective pathogen-effector repertoire. We hypothesize that the variable levels of basal resistance observed during interactions between Ciborinia camelliae and Camellia spp. are also due to the variable effectiveness of Ciborinia camelliae's effectors in phylogenetically divergent hosts.

We confirmed the susceptibility of the common ornamental species Camellia japonica subsp. japonica but did not assess the other two ornamental genotypes, Camellia reticulata or Camellia sasanqua. However, other Camellia spp. belonging to the same sections of Camellia reticulata and Camellia sasanqua (section Camellia and section Oleifera) were all susceptible to Ciborinia camelliae infection. Confirmation that both Camellia sinensis var. sinensis and Camellia sinensis var. assamica form compatible interactions with Ciborinia camelliae (Fig. 4) may have implications for tea breeding, because fruit production is thought to be affected by this disease (13).

Comparative analysis revealed a correlation between Camellia sections and their levels of incompatibility to Ciborinia camelliae. Collectively, species of section Theopsis showed the highest levels of incompatibility, which makes them the preferable candidates for future resistance-breeding strategies. The creation of interspecific hybrids between the Theopsis and Camellia sections has been accomplished previously (1), suggesting that incompatible ornamental Camellia hybrids may already exist.

In conclusion, the observed incompatible Camellia lutchuensisCiborinia camelliae interactions are consistent with an induced plant defense response (16). The incompatible Camellia lutchuensis-Ciborinia camelliae interaction described here could be a useful model for characterizing genes associated with MTI in Camellia spp. How the described incompatible Camellia genotypes interact with the broad-host pathogens $S$. sclerotiorum and $B$. cinerea is of particular interest, because these economically important pathogens are closely related to Ciborinia camelliae (36). The establishment of compatible interactions with many species of Camellia suggests that Ciborinia camelliae secretes effectors during penetration and apoplastic growth. Furthermore, these effectors appear to vary in efficiency across the Camellia genus. Future goals will be to identify and characterize these floralorgan-specific effectors and determine their contribution toward pathogenicity. Based on this research, breeding durable, broadspectrum resistance into susceptible Camellia spp. appears to be a valid approach for combating Ciborinia camelliae infection.

\section{ACKNOWLEDGMENTS}

This work was supported by the New Zealand Camellia Memorial Trust and Gladys and Riggall Scholarship. We thank M. P. Cox for advice regarding statistical analyses as well as D. Hopcroft and J. Chen of the Manawatu Microscopy and Imaging Centre for their expertise regarding SEM and CLSM.

\section{LITERATURE CITED}

1. Ackerman, W. L. 1973. Species compatibility relationships within the genus Camellia. J. Hered. 64:356-358. 
2. Adaskaveg, J. E., Dieguez-Uribeondo, J., Forster, H., and Soto-Estrada, A. 2005. Subcuticular-intracellular hemibiotrophic and intercellular necrotrophic development of Colletotrichum acutatum on almond. Phytopathology 95:751-758.

3. Andrew, M., Barua, R., Short, S. M., and Kohn, L. M. 2012. Evidence for a common toolbox based on necrotrophy in a fungal lineage spanning necrotrophs, biotrophs, endophytes, host generalists and specialists. PLoS One 7:e29943.

4. Benjamini, Y., and Hochberg, Y. 1995. Controlling the false discovery rate-A practical and powerful approach to multiple testing. J. R. Stat. Soc. Ser. B Stat. Methodol. 57:289-300.

5. Chen, L., Zhou, Z.-X., and Yang, Y.-J. 2006. Genetic improvement and breeding of tea plant (Camellia sinensis) in China: From individual selection to hybridization and molecular breeding. Euphytica 154:239248.

6. De Wit, P. J. 1977. A light and scanning-electron microscopic study of the infection of tomato plants by the virulent and avirulent races of Cladosporium fulvum. Neth. J. Plant Pathol. 83:109-122.

7. Eaton, C. J., Cox, M. P., Ambrose, B., Becker, M., Hesse, U., Schardl, C. L., and Scott, B. 2010. Disruption of signaling in a fungal-grass symbiosis leads to pathogenesis. Plant Physiol. 153:1780-1794.

8. Fan, J., and Doerner, P. 2012. Genetic and molecular basis of nonhost disease resistance: complex, yes; silver bullet, no. Curr. Opin. Plant Biol. 15:400-406.

9. Fourie, J. F., and Holz, G. 1995. Initial infection processes by Botrytis cinerea on nectarine and plum fruit and the development of decay. Phytopathology 85:82-87.

10. Gomez-Gomez, L., and Boller, T. 2000. FLS2: An LRR receptor-like kinase involved in the perception of the bacterial elicitor flagellin in Arabidopsis. Mol. Cell 5:1003-1011.

11. Hansen, H. H., and Thomas, H. E. 1940. Flower blight of Camellias. Phytopathology 30:166-170.

12. Hao, X. Y., Yu, K., Ma, Q., Song, X. H., Li, H. L., and Wang, M. G. 2011. Histochemical studies on the accumulation of $\mathrm{H}_{2} \mathrm{O}_{2}$ and hypersensitive cell death in the nonhost resistance of pepper against Blumeria graminis $\mathrm{f}$. sp. tritici. Physiol. Mol. Plant Pathol. 76:104-111.

13. Hara, K. 1919. On a Sclerotinia disease of camellia. Dainippon Saurinkwaiho 436:29-31.

14. Heath, M. C. 2000. Nonhost resistance and nonspecific plant defenses. Curr. Opin. Plant Biol. 3:315-319.

15. Huckelhoven, R., Dechert, C., and Kogel, K. H. 2001. Non-host resistance of barley is associated with a hydrogen peroxide burst at sites of attempted penetration by wheat powdery mildew fungus. Mol. Plant Pathol. 2:199-205.

16. Jones, J. D. G., and Dangl, J. L. 2006. The plant immune system. Nature 444:323-329.

17. Jurick, W. M., and Rollins, J. A. 2007. Deletion of the adenylate cyclase (sacl) gene affects multiple developmental pathways and pathogenicity in Sclerotinia sclerotiorum. Fungal Genet. Biol. 44:521-530.

18. Kim, H. J., Chen, C. B., Kabbage, M., and Dickman, M. B. 2011. Identification and characterization of Sclerotinia sclerotiorum NADPH oxidases. Appl. Environ. Microbiol. 77:7721-7729.

19. Kim, K. S., Min, J. Y., and Dickman, M. B. 2008. Oxalic acid is an elicitor of plant programmed cell death during Sclerotinia sclerotiorum disease development. Mol. Plant-Microbe Interact. 21:605-612.

20. Kleemann, J., Rincon-Rivera, L. J., Takahara, H., Neumann, U., van Themaat, E. V. L., van der Does, H. C., Hacquard, S., Stuber, K., Will, I., Schmalenbach, W., Schmelzer, E., and O'Connell, R. J. 2012. Sequential delivery of host-induced virulence effectors by appressoria and intracellular hyphae of the phytopathogen Colletotrichum higginsianum. PLoS Pathog. 8:e1002643.

21. Kohn, L. M., and E. Nagasawa, E. 1984. A taxonomic reassessment of Sclerotinia camelliae Hara (Ciborinia camelliae Kohn), with observations on flower blight of Camellia. Jpn. Trans. Mycol. Soc. Jpn. 25:149-161.

22. Lamb, C., and Dixon, R. A. 1997. The oxidative burst in plant disease resistance. Annu. Rev. Plant Physiol. 48:251-275.

23. Lee, M. H., and Bostock, R. M. 2006. Induction, regulation, and role in pathogenesis of appressoria in Monilinia fructicola. Phytopathology 96:1072-1080

24. Levine, A., Tenhaken, R., Dixon, R., and Lamb, C. 1994. $\mathrm{H}_{2} \mathrm{O}_{2}$ from the oxidative burst orchestrates the plant hypersensitive disease resistance response. Cell 79:583-593.

25. Lipka, U., Fuchs, R., and Lipka, V. 2008. Arabidopsis non-host resistance to powdery mildews. Curr. Opin. Plant Biol. 11:404-411.

26. Molina, L., and Kahmann, R. 2007. An Ustilago maydis gene involved in $\mathrm{H}_{2} \mathrm{O}_{2}$ detoxification is required for virulence. Plant Cell 19:2293-2309.

27. Moose, S. P., and Mumm, R. H. 2008. Molecular plant breeding as the foundation for 21st century crop improvement. Plant Physiol. 147:969977.

28. Mysore, K. S., and Ryu, C. M. 2004. Nonhost resistance: How much do we know? Trends Plant Sci. 9:97-104

29. Niks, R. E., and Marcel, T. C. 2009. Nonhost and basal resistance: How to explain specificity? New Phytol. 182:817-828.

30. O'Connell, R. J., Thon, M. R., Hacquard, S., Amyotte, S. G., Kleemann, J., Torres, M. F., Damm, U., Buiate, E. A., Epstein, L., Alkan, N., Altmuller, J., Alvarado-Balderrama, L., Bauser, C. A., Becker, C., Birren, B. W., Chen, Z., Choi, J., Crouch, J. A., Duvick, J. P., Farman, M. A., Gan, P., Heiman, D., Henrissat, B., Howard, R. J., Kabbage, M., Koch, C., Kracher, B., Kubo, Y., Law, A. D., Lebrun, M. H., Lee, Y. H., Miyara, I., Moore, N., Neumann, U., Nordstrom, K., Panaccione, D. G., Panstruga, R., Place, M., Proctor, R. H., Prusky, D., Rech, G., Reinhardt, R., Rollins, J. A., Rounsley, S., Schardl, C. L., Schwartz, D. C., Shenoy, N., Shirasu, K., Sikhakolli, U. R., Stuber, K., Sukno, S. A., Sweigard, J. A., Takano, Y., Takahara, H., Trail, F., van der Does, H. C., Voll, L. M., Will, I., Young, S., Zeng, Q., Zhang, J., Zhou, S., Dickman, M. B., Schulze-Lefert, P., Ver Loren van Themaat, E., Ma, L. J., and Vaillancourt, L. J. 2012. Lifestyle transitions in plant pathogenic Colletotrichum fungi deciphered by genome and transcriptome analyses. Nat. Genet. 44:1060-1065.

31. Schulze-Lefert, P., and Panstruga, R. 2011. A molecular evolutionary concept connecting nonhost resistance, pathogen host range, and pathogen speciation. Trends Plant Sci. 16:117-125.

32. Segmuller, N., Kokkelink, L., Giesbert, S., Odinius, D., van Kan, J., and Tudzynski, P. 2008. NADPH oxidases are involved in differentiation and pathogenicity in Botrytis cinerea. Mol. Plant-Microbe Interact. 21:808819.

33. Sfondrini, N., and De Guadenzi, E. 2012. Web camellia register. International Camellia Society Web Register, Pavia, Italy. http://camellia. unipv.it/camelliadb2/

34. Solomon, P. S., and Oliver, R. P. 2001. The nitrogen content of the tomato leaf apoplast increases during infection by Cladosporium fulvum. Planta 213:241-249.

35. Solomon, P. S., and Oliver, R. P. 2002. Evidence that gamma-aminobutyric acid is a major nitrogen source during Cladosporium fulvum infection of tomato. Planta 214:414-420.

36. Taylor, C. H. 2004. Studies of Camellia flower blight (Ciborinia camelliae Kohn). Doctoral dissert. Massey University, Palmerston North, New Zealand.

37. Taylor, C. H., and Long, P. G. 2000. Review of literature on Camellia flower blight caused by Ciborinia camelliae. N. Z. J. Crop Hortic. 28:123-138.

38. Thordal-Christensen, H., Zhang, Z. G., Wei, Y. D., and Collinge, D. B. 1997. Subcellular localization of $\mathrm{H}_{2} \mathrm{O}_{2}$ in plants. $\mathrm{H}_{2} \mathrm{O}_{2}$ accumulation in papillae and hypersensitive response during the barley-powdery mildew interaction. Plant J. 11:1187-1194.

39. Uma, B., Rani, T. S., and Podile, A. R. 2011. Warriors at the gate that never sleep: Non-host resistance in plants. J. Plant Physiol. 168:21412152.

40. van Esse, H. P., Bolton, M. D., Stergiopoulos, I., de Wit, P. J., and Thomma, B. P. 2007. The chitin-binding Cladosporium fulvum effector protein Avr4 is a virulence factor. Mol. Plant-Microbe Interact. 20:10921101.

41. van Esse, H. P., Van't Klooster, J. W., Bolton, M. D., Yadeta, K. A., van Baarlen, P., Boeren, S., Vervoort, J., de Wit, P. J., and Thomma, B. P. 2008. The Cladosporium fulvum virulence protein Avr2 inhibits host proteases required for basal defense. Plant Cell 20:1948-1963.

42. Van Toor, R. F., Dench, M. W., Jaspers, M. V., and Stewart, A. 2005. Tree mulches reduce sclerotial numbers and apothecial production by Ciborinia camelliae. N. Z. J. Crop Hortic. 33:161-168.

43. Van Toor, R. F., Jaspers, M. V., and Stewart, A. 2005. Effect of soil microorganisms on viability of sclerotia of Ciborinia camelliae, the causal agent of Camellia flower blight. N. Z. J. Crop Hortic. 33:149-160.

44. Van Toor, R. F., Jaspers, M. V., and Stewart, A. 2005. Wood rotting fungi and pine mulches enhance parasitism of Ciborinia camelliae sclerotia in vitro. N. Z. J. Crop Hortic. 33:389-397.

45. Vijayan, K., Zhang, W.-J., and Tso, C.-H. 2009. Molecular taxonomy of Camellia (Theaceae) inferred from nrITS sequences. Am. J. Bot. 96:13481360.

46. Williams, B., Kabbage, M., Kim, H. J., Britt, R., and Dickman, M. B. 2011. Tipping the balance: Sclerotinia sclerotiorum secreted oxalic acid suppresses host defenses by manipulating the host redox environment. PLoS Pathog. 7:e1002107.

47. Wilson, R. A., and Talbot, N. J. 2009. Under pressure: Investigating the biology of plant infection by Magnaporthe oryzae. Nat. Rev. Microbiol. 7:185-195. 